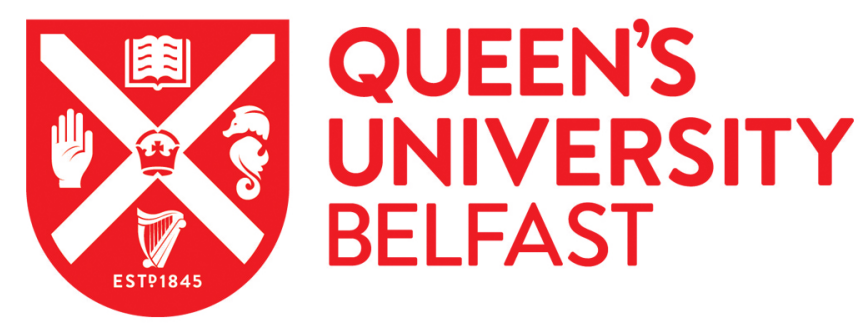

\title{
Differential Interaction Strengths and Prey Preferences Across Larval Mosquito Ontogeny by a Cohabiting Predatory Midge
}

Cuthbert, R., Callaghan, A., \& Dick, J. (2019). Differential Interaction Strengths and Prey Preferences Across Larval Mosquito Ontogeny by a Cohabiting Predatory Midge. Journal of Medical Entomology. https://doi.org/10.1093/jme/tjz059

Published in:

Journal of Medical Entomology

Document Version:

Peer reviewed version

Queen's University Belfast - Research Portal:

Link to publication record in Queen's University Belfast Research Portal

Publisher rights

(c) 2019 Oxford University Press. This work is made available online in accordance with the publisher's policies. Please refer to any applicable terms of use of the publisher.

\section{General rights}

Copyright for the publications made accessible via the Queen's University Belfast Research Portal is retained by the author(s) and / or other copyright owners and it is a condition of accessing these publications that users recognise and abide by the legal requirements associated with these rights.

Take down policy

The Research Portal is Queen's institutional repository that provides access to Queen's research output. Every effort has been made to ensure that content in the Research Portal does not infringe any person's rights, or applicable UK laws. If you discover content in the Research Portal that you believe breaches copyright or violates any law, please contact openaccess@qub.ac.uk. 
3 Differential Interaction Strengths and Prey Preferences across Larval Mosquito

\section{Ontogeny by a Cohabiting Predatory Midge}

5

6 Ross N. Cuthbert ${ }^{1,2 *}$, Amanda Callaghan ${ }^{2}$, Jaimie T.A. Dick ${ }^{1}$

$8{ }^{1}$ Institute for Global Food Security, School of Biological Sciences, Medical Biology Centre,

9 Queen's University Belfast, Belfast BT9 7BL, Northern Ireland

$10{ }^{2}$ Ecology and Evolutionary Biology, School of Biological Sciences, University of Reading,

11 Harborne Building, Whiteknights, Reading RG6 6AS, England

*Corresponding author: email, rcuthbert03@qub.ac.uk 


\section{Abstract}

22 Understandings of natural enemy efficacy are reliant on robust quantifications of interaction strengths under context-dependencies. For medically important mosquitoes, rapid growth during aquatic larval stages could impede natural enemy impacts through size refuge effects. The identification of biocontrol agents which are unimpeded by ontogenic size variability of prey is therefore vital. We use functional response and prey preference experiments to examine the interaction strengths and selectivity traits of larvae of the cohabiting predatory midge Chaoborus flavicans (Meigen 1830) (Diptera: Chaoboridae) towards larval stages of the Culex pipiens (Diptera: Culicidae) mosquito complex. Moreover, we examine the influence of search area variation on selectivity traits, given its importance in consumerresource interactions. Chaoborids were able to capture and consume mosquito prey across their larval ontogeny. When prey types were available individually, a destabilising Type II functional response was exhibited towards late instar mosquito prey, whilst a more stabilising Type III functional response was displayed towards early instars. Accordingly, search efficiencies were lowest towards early instar prey, whilst, conversely, maximum feeding rates were highest towards this smaller prey type. However, when the prey types were present simultaneously, C. flavicans exhibited a significant positive preference for late instar prey, irrespective of water volume. Our results identify larval chaoborids as efficacious natural enemies of mosquito prey, with which they frequently coexist in aquatic environments. In particular, an ability to prey on mosquitoes across their larval stages, coupled with a preference for late instar prey, could enable high population-level offtake rates and negate compensatory reductions in intraspecific competition through size refuge.

\section{Keywords}


Predatory natural enemies can drive population-level suppression of medically important vector species (Cameron and Lorenz 2013; Cuthbert et al. 2018a). However, a lack of aerial dispersal capability limits the efficacy of many biological control agents by inhibiting colonization of patchy aquatic habitats across landscapes (Cuthbert et al. 2019c). Given that vector mosquito species successfully colonize minute, ephemeral aquatic habitats of changeable volumes, an impediment to applications of common natural enemies is presented (e.g. fish, Azevedo-Santos et al. 2017). Furthermore, refuge effects relating to prey size can reduce the suppressive efficacy of biological control agents towards target populations across ontogenic stages (Kesavaraju et al. 2007; Marten and Reid 2007). For example, species which only effectively predate early instar larval stages may, paradoxically, alleviate resource competition among individual mosquitoes in later instar stages within aquatic ecosystems, if not all prey are consumed. In turn, this may produce better disease vectors via positive effects on adult health and longevity (Juliano et al. 2014). Thus, the identification of biological control agents which are able to effectively prey on mosquito prey across their larval ontogeny is crucial, particularly given the rapidity at which mosquitoes can complete development, and their capability to vector pathogens and parasites which cause disease (Juliano 2007; Cuthbert et al. 2018b).

Coexisting predatory dipterans have been identified as potentially efficacious natural enemies for controlling mosquito populations in their aquatic larval stages (Borkent 1980; Griswold and Lounibos 2005; Cuthbert et al. 2019a, b). In particular, capabilities for natural aerial dispersal in adult stages may promote simultaneous colonization of ephemeral aquatic habitats by predatory dipteran larvae, helping to reduce mosquito abundances. The present study thus uses functional responses (resource use under different resource densities; Holling 1959) and prey preferences to quantify interaction strengths of larvae of the predatory non- 
biting midge Chaoborus flavicans (Meigen 1830) (Diptera: Chaoboridae) towards larvae of

\section{Experimental design}

\section{Materials and Methods} the medically important Culex pipiens (Diptera: Culicidae) mosquito complex across their larval ontogeny. Chaoborids are known to colonise various types of aquatic habitats where mosquitoes breed, including artificial containers (e.g. Sunahara et al. 2002). Focusing on container-style aquatic systems, we additionally examine whether differences in search area further influence consumptive traits of this focal ambush predator, given the importance of search area in mediating consumer-resource interaction strengths (Uiterwaal and DeLong 2018). We hypothesise that: (1) chaoborids will exhibit a higher magnitude functional response towards early instar mosquitoes; and, (2) a consumptive preference will be exhibited towards early instar mosquito stages compared to late instars, owing to their smaller size, irrespective of search area differences.

\section{$\underline{\text { Animal collection and maintenance }}$}

Fourth instar larval Chaoborus flavicans were purchased commercially (10 - $12 \mathrm{~mm}$; Northampton Reptile Centre, Northampton). These predatory chaoborids were maintained at $11 \pm 1{ }^{\circ} \mathrm{C}$ and under a $12 \mathrm{~h}: 12 \mathrm{~h}$ light and dark regime until experimentation in a laboratory at Queen's Marine Laboratory (QML), Portaferry. Chaoborids were fed ad libitum with larval mosquitoes. Predators were isolated and starved for $24 \mathrm{~h}$ prior to the experiments individually. The prey, larvae of the $C$. pipiens mosquito complex, were obtained from a colony maintained at QML, Portaferry, reared as per Cuthbert et al. (2018a). Prey larval stages used in experiments were multi-generational.

In the functional response experiment, early (first instar, $1-2 \mathrm{~mm}$ ) or late (fourth instar, 4 $5 \mathrm{~mm}$ ) larval mosquito prey were introduced separately at five densities $(2,4,8,16$ and 32;n 
$94=6$ per experimental group) in $50 \mathrm{~mL}$ arenas of $65 \mathrm{~mm}$ diameter containing dechlorinated tap water from a continually aerated source. These size classes correspond to $C$. pipiens complex instar stages reared in similar conditions in other studies (e.g. Cuthbert et al. 2018b; Dalal et al. 2019). Two hours later, to allow for prey to acclimatize, predatory chaoborids were introduced individually and allowed to feed undisturbed for $24 \mathrm{~h}$, after which predators were removed and live prey remaining were enumerated. Pilot studies indicated that this acclimation time was appropriate for prey to settle within the experimental arenas. Controls consisted of 6 replicates at each prey density and prey size class in the absence of predators.

In the preference experiment, early and late instar mosquito prey (stages/sizes as before) were introduced simultaneously ( $n=15$ per prey type) to containers of either $50 \mathrm{~mL}$ or $200 \mathrm{~mL}$ volume with dechlorinated tap water, of $65 \mathrm{~mm}$ and $115 \mathrm{~mm}$ diameter, respectively. After settling as before, predatory chaoborids were introduced individually and allowed to feed for $24 \mathrm{~h}$, before remaining live prey of each size class were counted for each volume treatment. Treatments were replicated 6 times, and controls consisted of six predatorfree replicates.

\section{$\underline{\text { Statistical analyses }}$}

Data analyses were performed using R v3.4.4 (R Core Development Team 2018). In the functional response experiment, overall prey consumption was analysed using generalized linear models assuming a Poisson error distribution with log link. Model averaging was used to identify models which minimized information loss using second order Akaike's Information Criterion (AICc) (Burnham and Anderson 2002; Bartoń 2015). Tukey’s tests were used for post hoc comparisons of significant effects (Lenth 2016).

Functional response analyses were performed using the 'frair' package (Pritchard et al. 2017). Logistic regression was used to categorize functional response types, wherein a 
118 Type II functional response is evidenced by a significantly negative first order term, and a

119 Type III functional response by a significantly positive first order term followed by a significantly negative second order term (Juliano 2001). A generalized form of the functional response was implemented, assuming no prey replacement (Real 1997; Pritchard et al. 2017):

$$
N_{e}=N_{0}\left(1-\exp \left(b N_{0}^{q}\left(h N_{e}-T\right)\right)\right)
$$

where $N_{e}$ is the number of prey eaten, $N_{0}$ is the initial prey density, $b$ is the search coefficient, $h$ is the handling time, $q$ is the scaling exponent and $T$ is the total time available. The scaling exponent $q$ can be fixed at 0 where a categorical Type II functional response is evidenced. Where functional responses types are equivocal, $q$ can be optimized to provide flexibility in functional response fits, where $q>0$ indicates movement towards a sigmoid Type III curve. Suitability of models was examined using AIC. Locally Weighted Scatterplot Smoothing (LOWESS) lines were also plotted (9/10 smoother span) to further illustrate functional response forms. Functional response curves were then non-parametrically bootstrapped to generate $95 \%$ confidence intervals. error distribution and log link were used to examine the influence of prey size and water volume on consumption (Bates et al. 2015). Owing to repeated measures, each replicate was included as a random effect, with prey type treated as a within-subject variable. Model averaging was implemented during model selection based on AICc. Manly's selectivity index between prey types was employed to account for prey depletion over the experimental period (Manly 1974; Chesson 1983).

$$
\alpha_{i}=\ln \left(\left(n_{i o}-r_{i}\right) / n_{i o}\right) / \sum_{j=1}^{m} \ln \left(\left(n_{j 0}-r_{j}\right) / n_{j 0}\right)
$$


where $a_{i}$ is Manly's selectivity index for prey type $i, n_{i o}$ is the number of prey type $i$ available at the start of the experiment, $r_{i}$ is the number of prey type $i$ consumed, $m$ the number of prey types, $r_{j}$ is the number of prey type $j$ consumed and $n_{j 0}$ the number of prey type $j$ available at the start of the experiment. The value of $\alpha_{i}$ ranges from 0 to 1 , with 0 indicating complete avoidance and 1 indicating complete positive selection. In a two prey system, values $>0.5$ are indicative of preference towards the focal prey type.

\section{Results}

Over $99.5 \%$ of larval mosquito prey survived in control groups, and thus prey deaths were attributed to predation in both experiments. In the functional response experiment, 9.07, $\mathrm{df}=1, p=0.003)$, and greater numbers of prey were consumed where more prey were available $\left(\chi^{2}=80.95, \mathrm{df}=4, p<0.001\right)$. There was a significant interaction between these terms $\left(\chi^{2}=11.55, \mathrm{df}=4, p=0.02\right)$, with consumption between the two prey size classes more similar at low densities as compared to high densities (Figure 1; Figure 2).

Chaoborids displayed an equivocal functional response form towards early instar mosquito prey (Table 1). A flexible model with scaling exponent $q$ fixed at 1 was, however, shown to minimise information loss. On the other hand, a significant Type II functional response was demonstrated towards late instar mosquito prey, and thus $q$ was fixed at 0 here (Table 1). These functional response forms were further evidenced by LOWESS lines, with proportional early instar consumption initially rising before subsequently decreasing at higher prey densities, whilst, contrastingly, late instar proportional consumption was consistently reduced across all increasing densities (Figure 2). Search coefficients by chaoborids tended to be lower towards early instar mosquito prey, further evidenced by inflection and divergence between prey types at low densities (Table 1; Figure 1). Handling times, however, were also 
significantly reduced towards early instar prey than later instar prey, causing higher maximum feeding rates towards this smaller prey type (Table 1; Figure 1).

In the prey preference experiment, significantly greater numbers of late instar prey were consumed than early instar prey overall $\left(\chi^{2}=4.06, \mathrm{df}=1, p=0.04\right)$. There was no significant difference in overall prey consumption between container water volumes $\left(\chi^{2}=\right.$ $0.07, \mathrm{df}=1, p=0.79)$ and the preference for late instar prey was evident across both volume types, owing to a non-significant interaction term $\left(\chi^{2}=0.13, \mathrm{df}=1, p=0.72\right)$. Selectivity indices were thus higher towards late instar mosquito prey compared to early instar prey irrespective of the container volume treatment (Figure 3).

\section{Discussion}

In the present study, larval $C$. flavicans were able to effectively capture and consume both early and late instar larval C. pipiens prey. However, there were considerable differences in interaction strengths according to target prey size/ontogeny. Whilst chaoborids exhibited a significantly higher maximum feeding rate (functional response asymptote) towards the smaller early instars, the search efficiency (functional response initial slope) towards this prey type was reduced compared to larger late instar mosquito prey. These consumptive propensities are also reflected in the differential functional response forms observed, with predation towards late instar prey categorized as a Type II form, wherein proportional prey consumption at low prey densities was high. Conversely, a Type III functional response was exhibited towards early instar prey, owing to low prey consumption rates at low prey densities. Given that Type III functional responses can be stabilizing to populations due to density-dependent refugia (Murdoch and Oaten 1975), predatory chaoborid larvae may impart a degree of stability to early instar mosquito prey populations. Nevertheless, as early instar larval mosquito prey progress through subsequent ontogenic stages, an increased search 
efficiency and selective preference may enable high consumption of remaining large prey. Thus, any early instar low-density prey refuge imparted by chaoborids may be offset by intensified interaction strengths towards later instar stages at low densities. In turn, this could negate intraspecific competition alleviation in larval mosquitoes, which has been suggested to produce better vectors (Juliano et al. 2014).

Here, larval chaoborids exhibited a significant positive preference for late instar mosquito prey, despite the longer handling time required for this prey type. This selective propensity was prevalent irrespective of search volume, which has been shown to strongly influence consumer-resource interactions in other experimental systems (Uiterwaal and Delong 2018). Chaoborids are ambush predators which capture nearby prey through hydromechanical cue reception (Riessen et al. 1984), and are known to impact mosquito larval abundances in container-style aquatic habitats (Sunahara et al. 2002). It is probable that larger prey are more prevalent to this ambush predator, driving a selective preference and higher search efficiency through strong hydromechanical signalling. Given that positive selection of late instar larval mosquito prey is favourable for the biological control of medically important populations (Juliano 2007), use of predatory natural enemies which positively select late instar prey, naturally coexist with mosquitoes and which are also capable of aerial dispersal could assist in population-level suppression.

Although multi-generational larval mosquito prey were utilised in the present study, chaoborids have also been shown to be efficacious predators of wild-caught larval mosquitoes under different environmental contexts (Cuthbert et al. 2019b). Furthermore, wild C. pipiens oviposition has been shown to be undeterred by the presence of larval chaoborids, which may further enhance their predatory impacts (Cuthbert et al. 2019b). We thus propose that the promotion of chaoborids in environments, or deliberate introduction, could assist in mosquito population management strategies. However, examinations of prey selectivity traits 
across larval chaoborid ontogenic variations are also required, alongside integrations of predator population-level responses to resource availability (i.e. numerical response) under different environmental contexts. Overall, the combined testing of per capita interaction strengths alongside prey preferences offers great utility in the quantification of natural enemy efficacies under context-dependencies.

\section{Acknowledgements}

We acknowledge funding from the Department for the Economy, Northern Ireland.

\section{References}

Azevedo-Santos, V. M., J. R. S. Vitule, F. M., Pelicice, E. García-Berthou, and D. Simberloff. 2017. Nonnative fish to control Aedes mosquitoes: a controversial, harmful tool. BioScience 67: 84-90.

Bartoń, K. 2015. MuMIn: Multi-model inference. R package

Bates, D., M. Maechler, B. Bolker, and S. Walker. 2015. Fitting linear mixed-effects models using lme4. J.Stat. Softw. 67: 1-48.

Borkent, A. 1980. The potential use of larvae of Chaoborus cooki Sakther (Diptera: Chaoboridae) as a biological control of mosquito larvae. Mosq. News 40: 634-635.

Burnham, K. P., and D. R. Anderson. 2002. Model selection and multimodel inference: A practical information-theoretic approach. Springer-Verlag, New York, United States.

Cameron, M. M., and L. M. Lorenz. 2013. Biological and Environmental Control of Disease Vectors. CABI International, Wallingford, United Kingdom.

Chesson, J. 1983. The estimation and analysis of preference and its relationship to foraging models. Ecology 64: 1297-1304. 
Cuthbert, R. N., R. Al-Jaibachi, T. Dalu J. T. A. Dick, and A. Callaghan. 2019a. The influence of microplastics on trophic interaction strengths and oviposition preferences of dipterans. Sci. Total Environ. 651: 2420-2423.

Cuthbert, R. N., T. Dalu, R. J. Wasserman, A. Callaghan, O. L. F. Weyl, and J. T. A. Dick. 2018b. Calanoid copepods: An overlooked tool in the control of disease vector mosquitoes. J. Med. Entomol. 55: 1656-1658.

\section{Cuthbert, R. N., T. Dalu, R. J. Wasserman, A. Callaghan, O. L. F. Weyl, and J. T. A.} Dick. 2019c. Using functional responses to quantify notonectid predatory impacts across increasingly complex environments. Acta Oecol. In press.

Cuthbert, R. N., J. T. A. Dick, A. Callaghan, and J. W. E. Dickey. 2018a. Biological control agent selection under environmental change using functional responses, abundances and fecundities; the Relative Control Potential (RCP) metric. Biol. Control 121: 50-57.

Cuthbert R.N., N. Ortiz-Perea, J.T.A. Dick, and A. Callaghan. 2019b. Elusive enemies: consumptive and ovipositional effects on mosquitoes by predatory midge larvae are enhanced in dyed environments. Biol. Control. 132: 116-121.

Dalal, A., Cuthbert, R.N., Dick, J.T.A., and Gupta, S. 2019. Water depth-dependent notonectid predatory impacts across larval mosquito ontogeny. Pest Manage. Sci. in press.

Griswold, M. W., and L. P. Lounibos. 2005. Does differential predation permit invasive and native mosquito larvae to coexist in Florida? Ecol. Entomol. 30: 122-127.

Holling, C. S. 1959. Some characteristics of simple types of predation and parasitism. Can. Entomol. 91: 385-398. 
Juliano, S. A. 2001. Non-linear curve fitting: predation and functional response curves, pp. 178-196. In S. M. Scheiner and J. Gurevitch (eds.), Design and analysis of ecological experiments. Oxford University Press, Oxford, United Kingdom.

Juliano, S. A. 2007. Population dynamics, pp. 265-275. In T. G. Floore. (ed.), Biorational Control of Mosquitoes. J. Am. Mosq. Contr. Assoc. 23.

Juliano, S. A., G. Sylvestre Ribeiro, R. Maciel-de-Freitas, M. G. Castro, C. Codeço, R. Lourenco-de-Oliveira, and L. P. Lounibos. 2014. She's a femme fatale: low-density larval development produces good disease vectors. Mem. Inst. Oswaldo Cruz 109: 96-103.

Kesavaraju, B., B. W. Alto, L. P. Lounibos, and S. A. Juliano. 2007. Behavioural responses of larval container mosquitoes to a size-selective predator. Ecol. Entomol. 32: $262-272$.

Lenth, R. V. 2016. Least-squares means: the R package 1smeans. J. Stat. Softw. 69: 1-33.

Manly, B. F. J. 1974. A model for certain types of selection experiments. Biometrics 30: $281-294$

Marten, G. G., and J. W. Reid. 2007. Cyclopoid copepods. J. Am. Mosq. Control Assoc. 23: $65-92$.

Murdoch, W. W., and A. Oaten. 1975. Predation and population stability. Adv. Ecol. Res. 9: $1-131$

Pritchard, D. W., R. Paterson, H. C. Bovy, and D. Barrios-O'Neill. 2017. Frair: an R package for fitting and comparing consumer functional responses. Methods Ecol. Evol. 8: 1528-1534. 
R Core Development Team. 2018. R: a language and environment for statistical computing.

R Foundation for Statistical Computing, Vienna, Austria.

284 Real, L. A. 1977. The kinetics of functional response. Am. Nat. 111: 289-300.

Riessen, H. P., W. J. O'Brien, and B. Loveless. 1984. An analysis of the components of Chaoborus predation on zooplankton and the calculation of relative prey vulnerabilities. Ecology 65: 514-522.

Sunahaha, T., Ishizaka, K., and Mogi, M. 2002. Habitat size: a factor determining the opportunity for encounters between mosquito larvae and aquatic predators. J. Vector Ecol. 27: 8-20.

Uiterwaal, S. F., and J. P. DeLong. 2018. Multiple factors, including arena size, shape the functional responses of ladybird beetles. J. Appl. Ecol. 55: 2429-2438.

(1) 
303 Table 1. Results from logistic regression considering proportional prey consumption as a

304 function of prey density, and functional response parameter estimations alongside associated

305 significance levels.

\begin{tabular}{|c|c|c|c|c|c|c|}
\hline Prey stage & $\begin{array}{l}\text { First order } \\
\text { term } \\
\text { (Type II), } \\
p\end{array}$ & $\begin{array}{l}\text { First order } \\
\text { term } \\
\text { (Type III), } \\
p\end{array}$ & $\begin{array}{l}\text { Second } \\
\text { order term } \\
\text { (Type III), } \\
p\end{array}$ & $\begin{array}{l}\text { Search } \\
\text { coefficient } \\
(b), p\end{array}$ & $\begin{array}{l}\text { Handling } \\
\text { time }(h), p\end{array}$ & $\begin{array}{l}\text { Maximum } \\
\text { feeding } \\
\text { rate }(1 / h)\end{array}$ \\
\hline $\begin{array}{l}\text { Early } \\
\text { instar }\end{array}$ & $-0.02,0.09$ & $0.08,0.14$ & $\begin{array}{l}-0.003, \\
0.08\end{array}$ & $\begin{array}{l}0.16,< \\
0.001\end{array}$ & $\begin{array}{l}0.07,< \\
0.001\end{array}$ & 14.48 \\
\hline Late instar & $\begin{array}{l}-0.06,< \\
0.001\end{array}$ & $-0.08,0.19$ & $\begin{array}{l}0.0005 \\
0.76\end{array}$ & $0.89,0.005$ & $\begin{array}{l}0.23,< \\
0.001\end{array}$ & 4.36 \\
\hline
\end{tabular}

306

307

308

309

310 


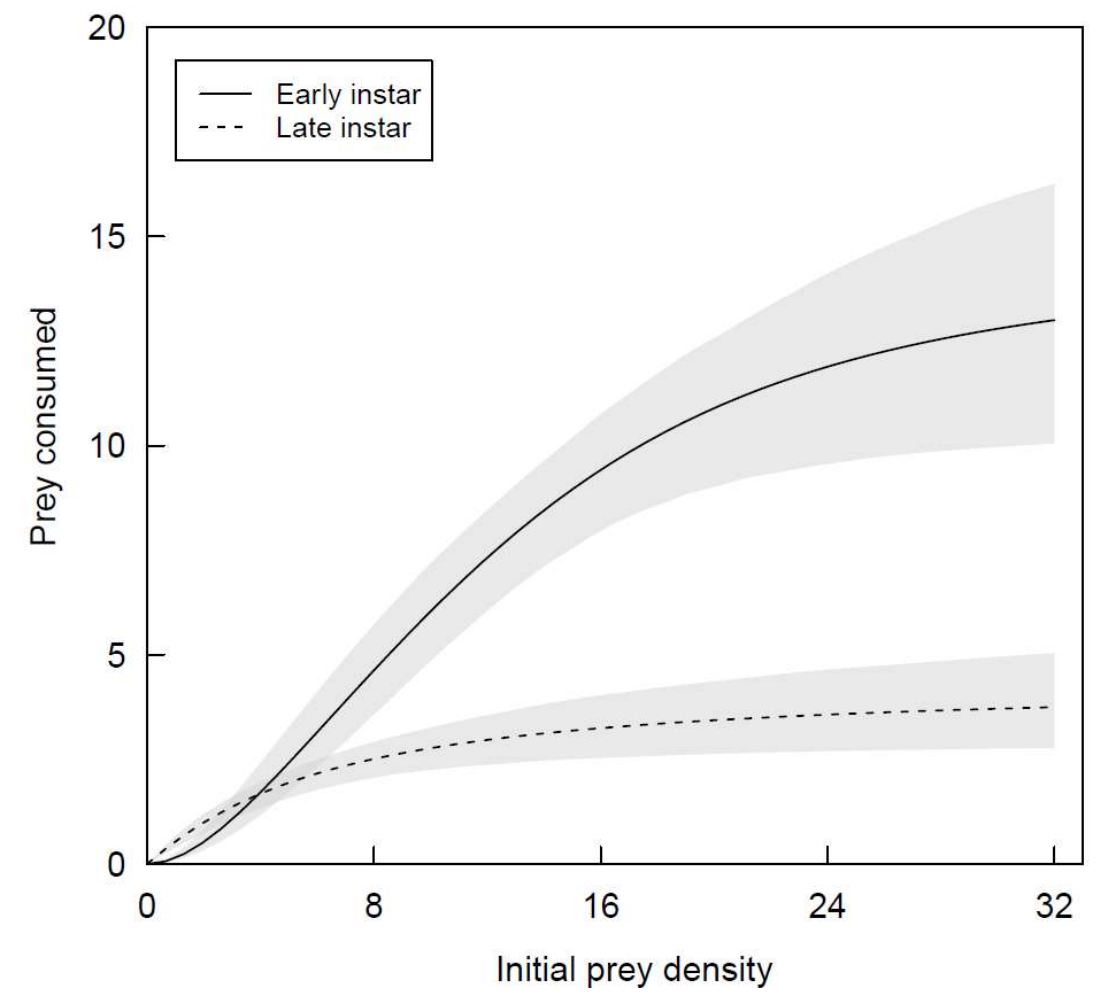

312

313 Figure 1. Functional responses of larval Chaoborus flavicans towards early and late instar

314 larval Culex pipiens prey. Shaded areas are bootstrapped $(n=2000) 95 \%$ confidence

315 intervals ( $n=6$ per experimental group).

316

317

318

319

320

321

322

323 


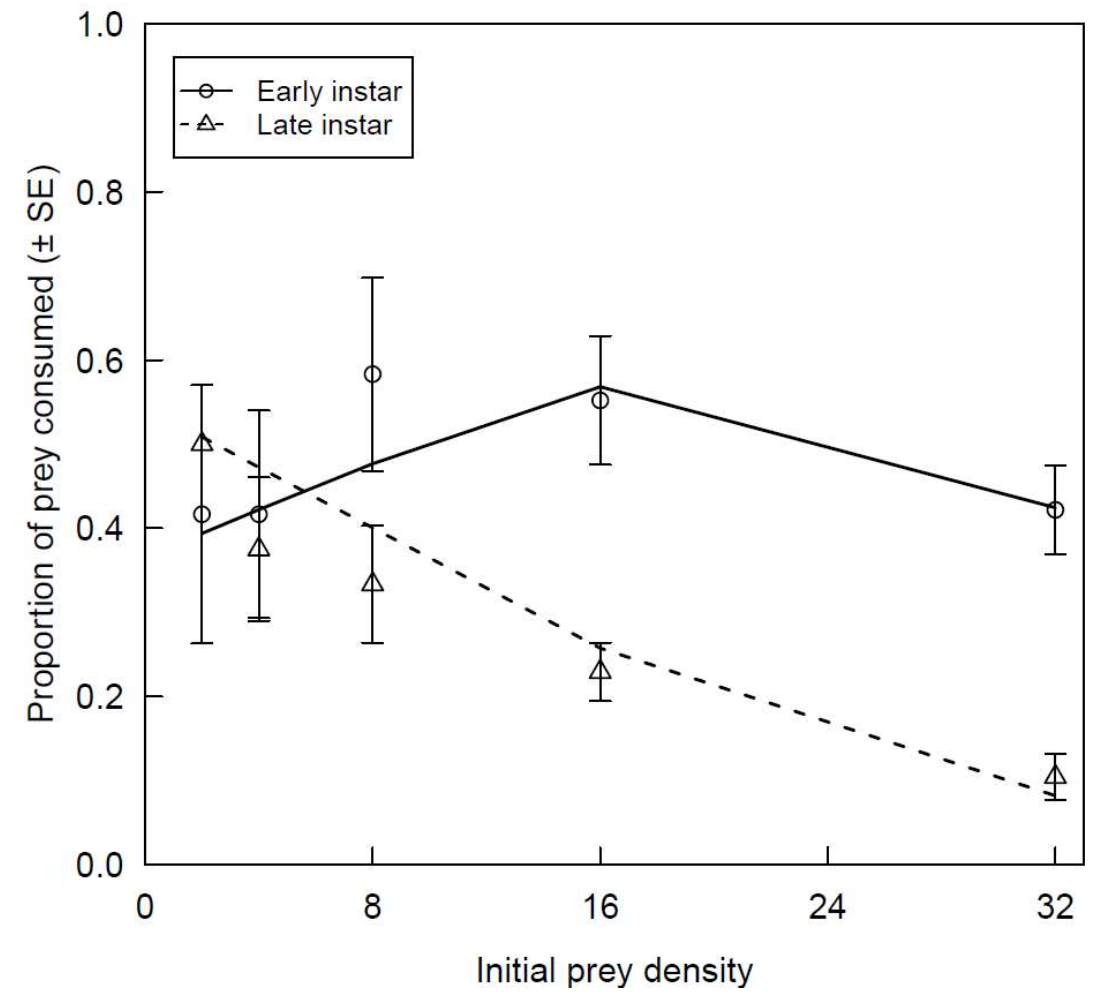

326 Figure 2. Locally Weighted Scatterplot Smoothing (LOWESS) lines considering proportional

327 prey consumption by larval Chaoborus flavicans as a function of larval Culex pipiens density 328 between different prey sizes. Points are mean values ( $n=6$ per experimental group). 


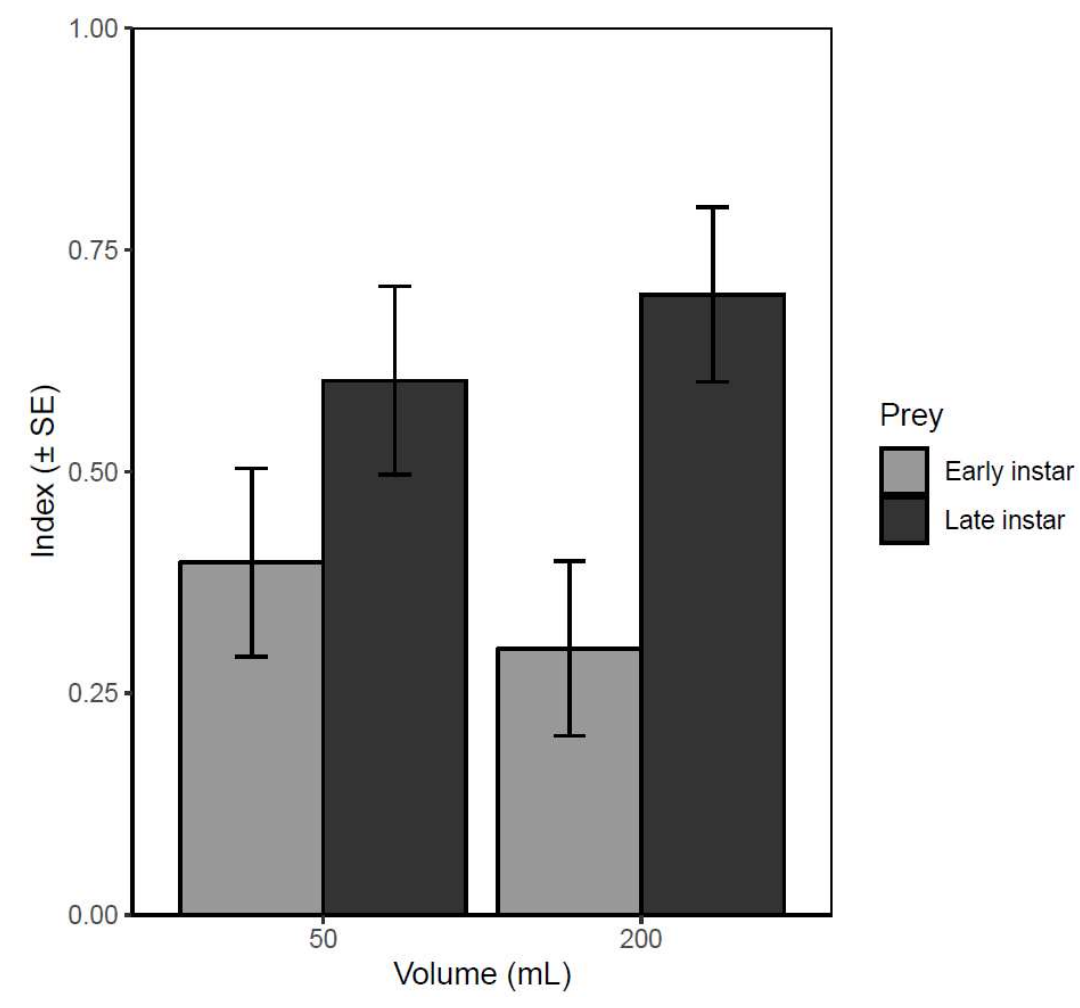

333 Figure 3. Mean Manly's selectivity indices towards early and late instar Culex pipiens prey

334 by larval Chaoborus flavicans. Values over 0.5 indicate active positive selection, whilst

335 values below 0.5 suggest avoidance ( $n=6$ per experimental group). 